\title{
Investigation of Capillary Limit in a Loop Heat Pipe
}

\author{
Jentung $\mathrm{Ku}_{\mathrm{a}}$ *, Laura Ottenstein a, Paul Rogers $\mathrm{b}$, Kwok Cheung $\mathrm{c}$ \\ a) NASA Goddard Space Flight Center, Greenbelt, Maryland, USA \\ b) U.S. Army TACOM, Warren, Michigan, USA, c) Naval Research Laboratory, Washington, D.C., USA
}

\begin{abstract}
This paper presets an experimental study on the capillary limit of a loop heat pipe (LHP) at low powers. The slow thermal response of the loop at low powers made it possible to observe interactions among various components after the capillary limit was exceeded. The capillary limit at low powers was achieved by imposing additional pressure drops on the vapor line through the use of a metering valve. A differential pressure transducer was also used to measure the pressure drop across the evaporator and the compensation chamber (CC). Test results show that when the capillary limit is exceeded, vapor will penetrate the primary wick, resulting in a partial dry-out of the evaporator and a rapid increase of the $\mathrm{CC}$ temperature. Because the evaporator can tolerate vapor bubbles, the LHP will continue to function and may reach a new steady state at the higher temperature. Thus, the LHP will exhibit a graceful degradation in performance rather than a complete failure. Moreover, the loop can recover from a partial dry-out by reducing the heat load without a re-start.
\end{abstract}

\subsection{Introduction}

Loop heat pipes (LHPs) are very versatile two-phase heat transport devices which can transfer large amounts of heat loads over long distances with small temperature differences [Maidanik 1985, Ku 1999]. LHPs have recently gained increasing acceptance as thermal control devices in spacecraft because of their robust operation and high capillary pumping capabilities. Extensive ground and flight tests have been conducted to characterize the LHP performance in terms of start-up, operating temperature, temperature hysteresis and temperature oscillations [Wolf and Bienert 1994, Cheung et al. 1998, Kaya and Ku 1999, Ku et al. 200la]. However, the heat transport limit of LHPs has not been investigated to any significant extent in the past. One reason is that the fine porous wick used in the evaporator has a very high pumping capability and thus a very large heat load is required in order to reach the capillary limit in a typical LHP. In many cases, the electrical heater attached to the evaporator exceeds its heat flux limit or the evaporator temperature becomes too high before the LHP reaches its capillary limit. In addition, the pressure drop data, which is a critical parameter in understanding the depriming process, is often unavailable because most LHPs are delivered as sealed units without pressure transducers.

A test program has been implemented to study the capillary limit of an LHP at low heat loads by installing a metering valve on the vapor transport line and a differential pressure transducer across the evaporator and the compensation chamber (CC). The slow thermal response resulting from small heat loads, along with the differential pressure readings, made it possible to study interactions among various LHP components after the capillary limit was exceeded. A theoretical analysis is presented first, followed by descriptions of the test article, test set-up, and test results.

\subsection{Theoretical Background}

Figure 1 shows the flow schematic of a typical LHP. The maximum capillary pressure that the primary wick is able to develop can be expressed as

$$
\Delta \mathrm{P}_{\text {cap, } \max }=2 \sigma / \mathrm{r}_{\mathrm{p}}
$$

where $\sigma$ is the surface tension of the working fluid and $r_{p}$ is the radius of the wick pores. As the heat load is applied to the evaporator, a flow rate will be established and a pressure drop will be incurred in each component 
of the LHP. The total pressure drop that the primary wick has to sustain is the sum of the pressure drops in the bayonet, primary wick, vapor grooves, vapor line, condenser, liquid line, and that due to the gravity head, i.e.

$$
\Delta \mathrm{P}_{\text {tot }}=\Delta \mathrm{P}_{\text {bay }}+\Delta \mathrm{P}_{\text {wick }}+\Delta \mathrm{P}_{\mathrm{gg}}+\Delta \mathrm{P}_{\text {vap }}+\Delta \mathrm{P}_{\text {cond }}+\Delta \mathrm{P}_{\text {liq }}+\Delta \mathrm{P}_{\mathrm{g}}
$$

In response to the pressure drop, the menisci at the vapor and liquid phase on the primary wick will curve naturally to yield a capillary pressure rise that matches the total pressure drop in the loop, i.e.

$$
\begin{aligned}
& \Delta \mathbf{P}_{\text {cap }}=2 \sigma / R_{p} \\
& \Delta \mathbf{P}_{\text {cap }}=\Delta \mathbf{P}_{\text {tot }}
\end{aligned}
$$

where $R_{p}$ is the radius of curvature developed at the liquid and vapor interface at the wick. Under normal operation, $\Delta P_{\text {tot }} \leq \Delta P_{\text {cap, max }}$ and $R_{p} \geq r_{p}$. The equal sign holds true when the capillary limit is reached. Any further increase of the total pressure drop will result in a failure of the wick, leading to a dry-out of the evaporator. Figure2 shows the corresponding pressure drop diagram for the LHP depicted in Figure 1.



Figure 1. Flow Schematic of an LHP

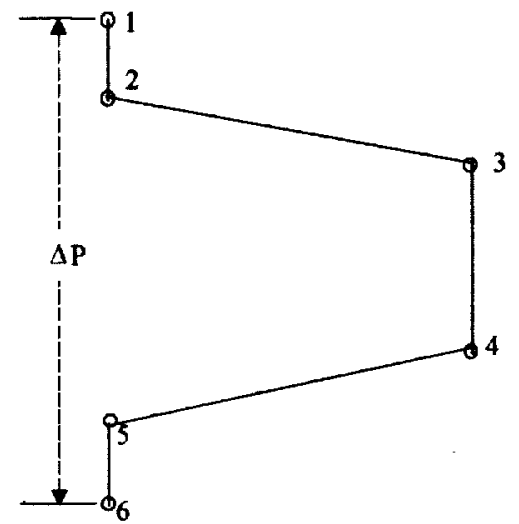

Figure 2. Pressure Drop Diagram

Since it is impossible or impractical to measure the pressure drop across the meniscus of the vapor and liquid interface, a differential pressure transducer is usually installed to measure the pressure drop across the evaporator and CC. The measured pressure drop corresponds to the sum of the last four terms in Eq. (2), and is equal to the pressure drop between point 2 and point 5 shown in Figure 2. In the following discussions, the measured pressure drop will be referred to as the external pressure drop. Because both the CC and the evaporator outer grooves contain two-phase fluid, a relationship exists between the temperature difference and the pressure difference of these components, as expressed by the Clausius-Clapeyron equation:

$$
\Delta \mathrm{P}=\lambda \Delta \mathrm{T} /\left(\mathrm{T}_{\mathrm{cc}} \Delta \mathrm{v}\right)=\lambda\left(\mathrm{T}_{\mathrm{e}}-\mathrm{T}_{\mathrm{cc}}\right) /\left(\mathrm{T}_{\mathrm{cc}} \Delta \mathrm{v}\right)
$$

The $\Delta P$ in Eq. (4) is equal to $\Delta P_{\text {tot }} . \Delta P_{\text {wick, }} \lambda$ is the latent heat of vaporization of the working fluid, $\Delta v$ is the difference in specific volume between the liquid and vapor phases, $\mathrm{T}_{e}$ is the vapor temperature in evaporator grooves, and $T_{c c}$ is $C C$ temperature. Thus, for a given pressure drop in the loop, a corresponding temperature difference exists between the evaporator and the CC. Such a temperature difference affects the heat leak from the evaporator to the $\mathrm{CC}$, which can be expressed as:

$$
Q_{\text {leak }}=G \Delta T=G\left(T_{e}-T_{c c}\right)
$$


where $\mathrm{G}$ is the thermal conductance between the evaporator and the $\mathrm{CC}$. The heat leak is a critical component in determining the $\mathrm{CC}$ saturation temperature, which in turn governs the loop operating temperature. The thermal conductance, $\mathrm{G}$, is usually very small if the evaporator core is completely filled with liquid, and becomes large if vapor exists in the evaporator core. The higher the vapor void fraction, the larger the heat leak [Ku et al. 2001b].

When the capillary limit is exceeded, vapor will penetrate the primary wick and reach the evaporator core, resulting in a rapid increase of the $\mathrm{CC}$ temperature. Two competing events will follow. First, the increasing $\mathrm{CC}$ temperature results in a decrease of the surface tension and the capillary pumping pressure, leading to even more vapor penetration and a further increase of the $\mathrm{CC}$ temperature. Second, as the $\mathrm{CC}$ temperature increases, more condenser area will be blocked with liquid, resulting in a smaller pressure drop. More importantly, the frictional pressure drops in evaporator grooves and transport lines will decrease due to decreasing vapor and liquid viscosities at the higher temperature. Thus, the loop may reach a new steady state with a higher operating temperature. At the new state, the total pressure drop is equal to or less than the capillary limit.

\subsection{Test Article and Test Set-up}

Figure 3 shows the schematic of the test article. The evaporator and the $\mathrm{CC}$ are made of stainless steel with an O.D. of $25.4 \mathrm{~mm}$, and lengths of $30.5 \mathrm{~mm}$ and $12.7 \mathrm{~mm}$, respectively. The primary wick is made of sintered powder nickel with a pore size of 1.2 microns and a permeability of $1.4 \times 10^{-14} \mathrm{~m}^{2}$. The vapor line has an I.D. of $3.34 \mathrm{~mm}$ and a length of $1.94 \mathrm{~m}$ while the liquid line has an $1 . D$. of $1.75 \mathrm{~mm}$ and is $2.1 \mathrm{~m}$ long. The condenser line has an I.D. of $3.86 \mathrm{~mm}$ and a length of $1.99 \mathrm{~m}$. . Ammonia is used as the working fluid. The capillary limit as a function of the temperature is shown in Figure 4.

An aluminum heater block with two cartridge heaters is attached to the evaporator to provide a total power up to $1200 \mathrm{~W}$. A heater is attached to the $\mathrm{CC}$ for temperature control, when needed. The condenser is cooled by a refrigerator. There are a total of 39 thermocouples. A differential pressure transducer is used to measure the pressure drop across the evaporator and $\mathrm{CC}$. A metering valve is installed on the vapor line to provide additional pressure drops when needed. A data acquisition system and the Labview software programs are used to monitor and store data. The simultaneous collection and display of temperature and differential pressure data using two computers and two monitors proves to be crucial in the understanding of interactions among various elements in LHP operation. Details of the test setup can be found in the literature [Ku et al. 200lb].

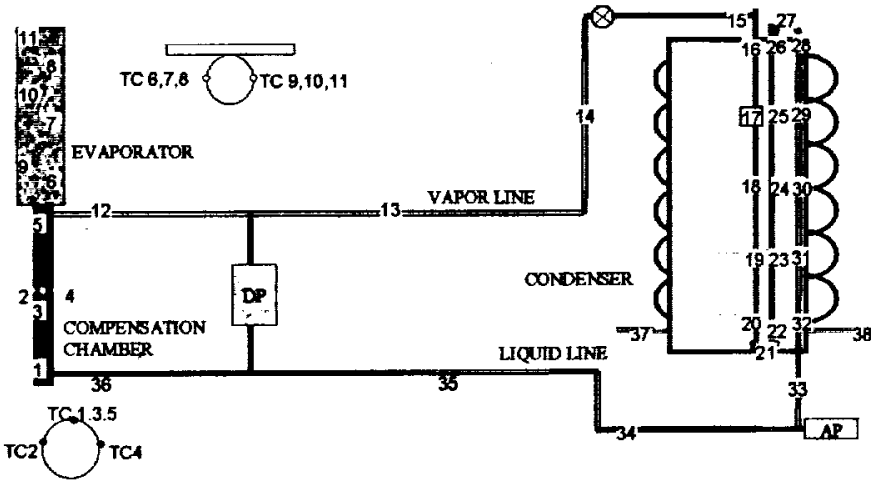

Figure 3 Schematic of the LHP

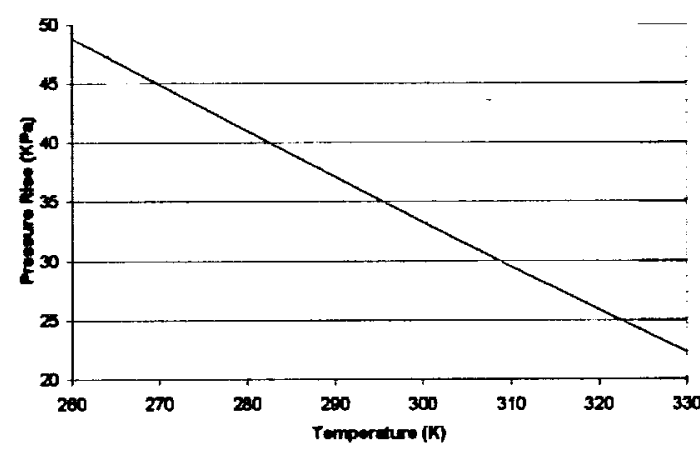

Figure 4 Capillary Limit versus Temperature

\subsection{Test Results}

Two different types of capillary limit tests were conducted. In the first type of test, the metering valve was closed at a fixed position, and the power was increased gradually until the capillary limit was exceeded. In the second type of test, the power to the evaporator was fixed and the metering valve was closed progressively until the capillary limit was exceeded. 


\subsection{Fixed Valve Setting}

Figure 5 illustrates the typical loop behavior in the first type of test. The loop started with $200 \mathrm{~W}$ at a sink temperature of $240 \mathrm{~K}$ while the metering valve was fully open. The operating temperature and the external pressure drop were $264.4 \mathrm{~K}$ and $1900 \mathrm{~Pa}$, respectively. The metering valve was then closed so as to yield an external pressure drop of $17000 \mathrm{~Pa}$. From Eqs. (5) and (6), a higher pressure drop led to a higher heat leak, and thus the loop operating temperature rose to $265.7 \mathrm{~K}$. With this fixed valve setting, the heat load was increased in steps: $250 \mathrm{~W} / 270 \mathrm{~W} / 280 \mathrm{~W}$. The external pressure drop increased with each power increase due to a higher flow rate. During the transient of power increase, there was an overshoot of the pressure drop, most likely due to the momentum change. The operating temperature happened to be constant around $265 \mathrm{~K}$ over this power range. As the heat load increased to $295 \mathrm{~W}$, the loop continued to operate at $265 \mathrm{~K}$ for 15 minutes during which time the pressure drop gradually increased to $36000 \mathrm{~Pa}$. Then the pressure drop suddenly decreased to $22000 \mathrm{~Pa}$ and the CC temperature jumped to $278 \mathrm{~K}$. Before the capillary limit was reached, the pressure drop had only very small oscillations. After the vapor penetration, the pressure drop oscillated between $16000 \mathrm{~Pa}$ and $26000 \mathrm{~Pa}( \pm 5000 \mathrm{~Pa}$ oscillations!). Right after the capillary limit was exceeded, very large spikes and dips of the differential pressure were observed, indicating vigorous interactions among loop components. Since the pressure drop after vapor penetration $(22000 \mathrm{~Pa})$ was much smaller than the capillary limit at the prevailing temperature of $278 \mathrm{~K}$ $(40000 \mathrm{~Pa})$, the vapor penetration should have stopped at the higher temperature.

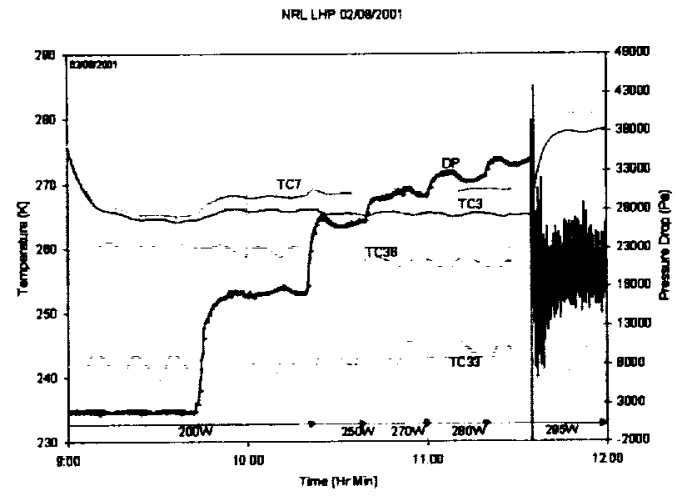

Figure 5. LHP Temperatures and Pressure Drop

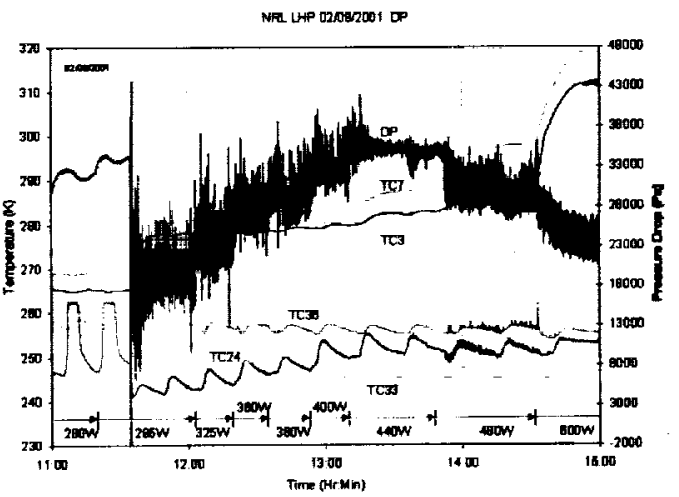

Figure 6. LHP Temperatures and Pressure Drop

The test was continued with the following heat loads: $325 \mathrm{~W} / 360 \mathrm{~W} / 380 \mathrm{~W} / 400 \mathrm{~W} / 440 \mathrm{~W}$. As shown in Figure 6 , the pressure drop increased with each power increase. Nevertheless, the capillary limit was not exceeded. As the power increased to $480 \mathrm{~W}$, vapor penetration occurred again. The CC temperature rose to $289 \mathrm{~K}$ and the differential pressure decreased from $34500 \mathrm{~Pa}$ to $30000 \mathrm{~Pa}$. Finally, as the heat load increased from $480 \mathrm{~W}$ to $600 \mathrm{~W}$, the $\mathrm{CC}$ temperature rose from $289 \mathrm{~K}$ to $312 \mathrm{~K}$, and the differential pressure gradually decreased to $23500 \mathrm{~Pa}$. The last power increase indicates that if the heat load far exceeded the maximum value, the loop operating temperature could increase rapidly.

Similar capillary limit tests were conducted at a sink temperature of $260 \mathrm{~K}$. Figure 7 shows the result of a typical test. The LHP started with a heat load of $200 \mathrm{~W}$ and the metering valve fully open. At the steady state, the loop operated at $277 \mathrm{~K}$ with an external pressure drop of $1300 \mathrm{~Pa}$. The $\mathrm{CC}$ temperature rose to $292 \mathrm{~K}$ when the metering valve was close to yield an external pressure drop of $17400 \mathrm{~Pa}$. With no change of the valve setting, the heat load was increased in steps until the capillary limit was exceeded and the loop operating temperature rose above $315 \mathrm{~K}$. When the heat load increased from $200 \mathrm{~W}$ to $300 \mathrm{~W}$, the differential pressure increased to $33000 \mathrm{~Pa}$ and then suddenly decreased to $22800 \mathrm{~Pa}$, indicating that vapor penetration had occurred. The vapor penetration resulted in a back flow of the warm fluid as evidenced by the temperature spike of the liquid return line TC36. After the transient, the CC temperature was steady at $297 \mathrm{~K}$ and the pressure drop was $30500 \pm 1200 \mathrm{~Pa}$. At 
$350 \mathrm{~W}$, the pressure drop increased to $32000 \mathrm{~Pa}$ and then became steady at $28000 \pm 1000 \mathrm{~Pa}$ as the $\mathrm{CC}$ temperature rose to $307 \mathrm{~K}$. Finally, as the power increased to $400 \mathrm{~W}$, the $\mathrm{CC}$ temperature rose to $322 \mathrm{~K}$ and the pressure drop decreased to $21000 \mathrm{~Pa}$. Thus, one can see a general pattern of the $\mathrm{CC}$ temperature and the pressure drop. After the capillary limit was exceeded at the prevailing temperature, vapor penetrated through the wick, resulting in the rise of the $\mathrm{CC}$ temperature. As the CC temperature was increasing, the pressure drop was decreasing due to lower fluid viscosities. The loop eventually reached a new steady state at a higher temperature. This process could be repeated. In this test, the upper limit of the CC temperature was set at $315 \mathrm{~K}$ beyond which no more power increase was allowed. Note that in the last two power levels, the temperature rose rapidly, indicating a higher vapor penetration rate. As the power decreased to $200 \mathrm{~W}$, the CC temperature dropped to $293 \mathrm{~K}$, close to the initial value of $292 \mathrm{~K}$, indicating a recovery. As the power increased to $400 \mathrm{~W}$ again, the pressure drop and the $\mathrm{CC}$ temperature rose to $33000 \mathrm{~Pa}$ and $321 \mathrm{~K}$, respectively. After the power increase, the differential pressure decreased with an increasing $\mathrm{CC}$ temperature.

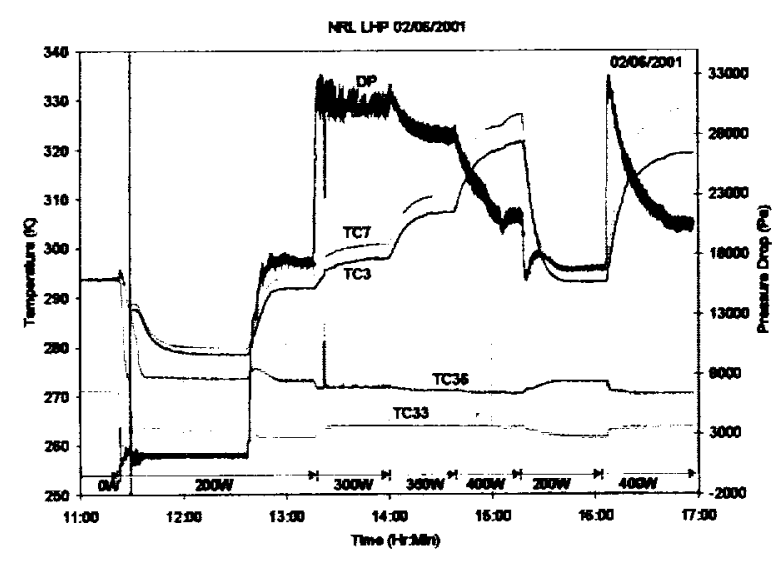

Figure 7. LHP Temperatures and Pressure Drop

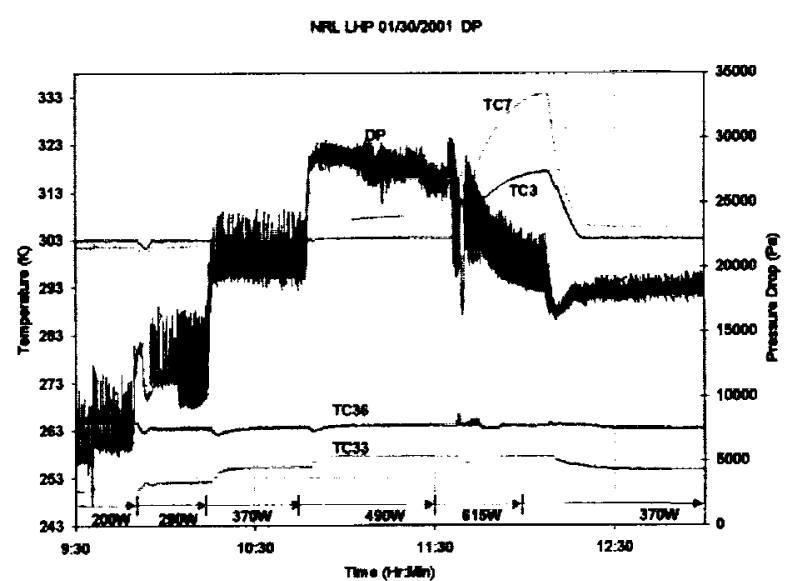

Figure 8. LHP Temperatures and Pressure Drop

The capillary limit test was also conducted with $\mathrm{CC}$ temperature controlled at a desired set point. Figure 8 shows the test at a sink temperature of $253 \mathrm{~K}$ and a CC temperature of $303 \mathrm{~K}$. From Figure 4, the capillary limit at $303 \mathrm{~K}$ is $32000 \mathrm{~Pa}$. Thus it was expected that vapor penetration would occur when the external pressure drop was near (slightly below) $32000 \mathrm{~Pa}$. The large pressure oscillations were caused by the on/off cycles of the CC heater. At each power increase, the pressure drop increased, but the $\mathrm{CC}$ temperature was controlled at $303 \mathrm{~K}$ for powers up to $490 \mathrm{~W}$. As the power increased to $615 \mathrm{~W}$, the $\mathrm{CC}$ temperature increased to $317 \mathrm{~K}$ and the pressure drop decreased from $30000 \mathrm{~Pa}$ to $22000 \mathrm{~Pa}$. The loop could no longer be controlled at $303 \mathrm{~K}$ because vapor penetration had occurred and the heat leak had increased substantially. Nevertheless, the loop was approaching a new steady state. The power was then decreased to $370 \mathrm{~W}$. The CC temperature was again under control at 303K. It is not clear why the pressure drop was lower than the previous value at the same power although the vapor front in the condenser was located around TC22 for both cases.

\subsection{Fixed Power}

The second type of the capillary limit test was conducted by keeping a constant heat load to the evaporator and gradually closing the metering valve until the capillary limit was exceeded. Figure 9 shows the typical loop behavior for a test conduct at a sink temperature of $273 \mathrm{~K}$ and a constant power of $200 \mathrm{~W}$. Initially, the valve was fully open, and the loop operated at $287 \mathrm{~K}$, yielding an external pressure drop of $1100 \mathrm{~Pa}$. As the valve was closed further to yield pressure drops of $19000 \mathrm{~Pa}$ and $26000 \mathrm{~Pa}$, the $\mathrm{CC}$ temperature rose to $295 \mathrm{~K}$ and $300 \mathrm{~K}$, respectively. These pressure drops were still below the capillary limit. The valve was then closed to yield a pressure drop of $30500 \mathrm{~Pa}$. The $\mathrm{CC}$ temperature gradually increased to $305 \mathrm{~K}$, and during this period the pressure drop gradually decreased to $27500 \mathrm{~Pa}$. As the valve was adjusted to yield an external pressure drop of $28500 \mathrm{~Pa}$, 
the CC temperature increased rapidly above $313 \mathrm{~K}$ and the differential pressure decreased to $22000 \mathrm{~Pa}$, indicating that vapor penetration had occurred. The valve was then opened slightly, and the $\mathrm{CC}$ temperature dropped quickly to $301 \mathrm{~K}$. Note that while the $\mathrm{CC}$ temperature was decreasing, the differential pressure was increasing because of increasing fluid viscosities at lower temperatures. This is also a good indication that vapor penetration had stopped. As the valve was openly further, the $\mathrm{CC}$ temperature dropped again. Finally, when the valve was fully open, the $\mathrm{CC}$ temperature decreased to $287 \mathrm{~K}$ and the differential pressure decreased to $1100 \mathrm{~Pa}$, the same as the initial values.

\subsection{Concluding Remarks}

Test results show that when the capillary limit of an LHP is exceeded, the CC temperature will increase rapid;y, presumably as a result of vapor penetration through the wick. Because the LHP could tolerate the vapor presence in the evaporator, the loop continued to operate. Although the capillary limit decreased with an increasing temperature, so did the fluid viscosities and the total pressure drop. Thus, it is possible for the loop to reach steady operation at a higher temperature. At the new state, the total pressure drop was equal to or lower than the capillary limit. Test results demonstrated that the capillary limit of the LHP could be exceeded repeatedly; each time led to a higher temperature. The pressure transducer was a very useful tool to verify such an event. In practical applications, there will seldom be a pressure transducer in the loop. Thus, the operator will only notice a sudden temperature increase in the $\mathrm{CC}$ when the capillary limit is exceeded. However, other factors may contribute to a sudden $\mathrm{CC}$ temperature increase, most notably a sudden bubble growth in the evaporator core $[\mathrm{Ku}$ et al. 2001b]. Thus, it may be difficult to tell whether or not the loop has reached its capillary limit by looking at the loop temperatures alone. The fact that the evaporator can tolerate vapor bubbles leads to a graceful degradation of the LHP performance instead of a complete failure when the capillary limit is exceeded. Moreover, the LHP can recover from a dry-out by lowering the heat load without the need for a restart. From the user's point of view, there is an upper limit in the CC temperature that can not be exceeded. Results of this study also indicate that the maximum power where such an upper temperature limit is exceeded can vary considerably from test to test, depending on the test history. This part of the test results was not reported here due to space limitations. Nevertheless, these facts make the concept of "the heat transport limit of an LHP" rather ambiguous. A corollary is that the LHP design should allow enough margins to ensure that the loop can transport the desired maximum heat load.

\section{References}

Cheung, M., Hoang, T., Ku, J., and Kaya, T, Thermal performance and operational characteristics of loop heat pipe (NRL LHP), SAE Paper No. 981813, (1998).

Kaya, T., and $\mathrm{Ku}$, J., "Investigation of the temperature hysteresis phenomenon of a loop heat pipe," 1999 National Heat Transfer Conference, Albuquerque, New Mexico, August 15-17, 1999.

Ku, J., Operating characteristics of loop heat pipes, SAE Paper No. 1999-01-2007, (1999).

Ku., J., Ottenstein, L., Kaya, T., Kobel, M., and Rogers, P., Temperature oscillations in loop heat pipe operation, STAIF 2001, American Institute of Physics, Albuquerque, New Mexico, February 11-14, 2001 .

Ku., J., Ottenstein, L., P. Rogers, and K. Cheung., Low power operation in a loop heat pipe, SAE Paper 2001-01-1992, (2001b).

Maidanik, Y. F., et al., Heat transfer apparatus, United States Patent No. 4515209 (1985).

Wolf, D., and Bienert, W., Investigation of temperature control characteristics of loop heat pipe, SAE Paper No. 941576, (1994). 